\title{
Research on the Effect of Population Quality on Economic Sustainable Development
}

\author{
Shuo Wang ${ }^{1, \text { a }}$ \\ ${ }^{1}$ Hainan Tropical Ocean Institute, Tourism Management Institute, Sanya, Hainan, China, 572000 \\ ${ }^{\mathrm{a} e m a i l,}$
}

Keywords: Population Quality, Economic Sustainable Development, Effect

\begin{abstract}
The economic sustainable development is important constituent of the overall sustainable development system, occupies the core status in the sustainable development system. Only when the economic sustainable development is realized, can the overall sustainable development system form. In the contemporary world, competition between the various countries is day by day intense, in the national strength competition the economic competition is the most basic and important aspect, moreover the Economic competition essence is the science and technology competition, is the knowledge competition and talented person's competition in the final analysis. Therefore, the population culture quality has the extremely important influence on the economic competition and the sustainable development.
\end{abstract}

\section{Introduction}

The overall level of economic development in China is still relatively low, the relative shortage of per capita resources, many indicators are below the world average level, population pressure, environmental pollution, with the rapid economic growth becomes severe, the overall level of scientific technology is not high, also illiterate there are as many as 200 million. Negative unfavorable factors make China's development of these serious constraints to be overcome, transformed for the benefit of sustained, rapid and steady growth of the positive factors and to ensure social stability, promoting social progress, its only option is to take the road of sustainable development. In the economy, society, population, resources and environment coordination premise of promoting the development of China's socialist modernization.

The core of sustainable development is to achieve coordinated economic and social development and population, resources and the environment and achieve sustainable development not only depends on economic growth indicators, but also the humanities, resources and environmental indicators. Although China has entered a stage of stabilizing the low fertility level, but the impact of man-days by the base, the population age structure, migration and socio-economic development process, is still very low level of human development, population issues impact on economic and social development is gradually increasing.

\section{Sustainable Development}

The current world economic output and basically to growth as the main indicator of socio-economic development, to enhance their overall economic strength, countries are to maximize the use of existing resources that can be obtained, but the resulting pair predatory use of resources, especially in the expense of the environment, one-sided pursuit of rapid economic growth mode of production and consumption patterns, has led to a series of questions to the globe. Humans for their own survival and development of future generations and continue to multiply, to seek a new development concept and development model put forward sustainable development became a historical necessity.

"Sustainable development" is a new development ideas and development strategies emerged in recent years, the international community, had been widely accepted around the world and become human development path 21st century goal. Different areas of the concept of sustainable development have focused on understanding, and some emphasis on environmental aspects, and 
some emphasis on economic aspects, as well as focus on social aspects. When most people talk about sustainable development, either from a broad understanding of the social and economic problems all comes down to sustainable development issues, or only the resource and environmental issues as the main elements of sustainable development in a narrow sense.

\section{The Basic Theory of Population Quality}

For epitaxial quality of the population, the traditional view that the quality of the population including physical, scientific and cultural quality and ideological and moral qualities in three aspects. Among them, the physical basis of the natural conditions and quality of the population, scientific and cultural quality is the ability of people to understand and transform the world, ideological and moral qualities of human behavior is the dominant state of consciousness. For many scholars dispute this argument, some believe that the quality of the population only by physical and scientific and cultural quality of the composition, on the grounds that: if the ideological and moral qualities included, due to the lack of a unified measure, it is difficult to carry out the international quality of the population comparison; even pan mankind must follow the code of ethics, classifying and quantifying indicators were also difficult to solve. The reason to use instead of the quality of scientific and cultural qualities of intelligence, because the illiterate population although it may lack the cultural and scientific aspects of literacy, but never lack a certain level of intellectual development; in other words, scientific and cultural qualities of the argument can not measure a large part in population Education culture and Science outside.

Above with respect to population quality epitaxial views, which vary, but all its rationality, can explain some problems. However, they seem to have made in the understanding of a same mistake that ignores the role of structural factors, some of the quality of the population is equivalent to the suspects Quality. System theory tells us that structure determines function. In other words, a certain population structure determines the population possesses the particular function. This feature can be a good indication of the quality of the natural population. In this sense we can say, it is part of the quality of the population structure of the population.

\section{The Impact on the Economic Development of the Quality Population}

Chinese population will continue to grow in the longer term, the next ten years the average annual net increase of more than 10 million people, the economy, society, resources, environment and sustainable development has brought enormous pressure; the lower the overall quality of the population's health a short time is difficult to change, and the requirements of the rapid development of science and technology in incompatible; a significant increase in the working-age person-days, high employment pressure; aging society in the economic situation is not yet developed to establish a comprehensive social security system increases difficulty; inter-regional economic and social development imbalances will persist, eliminating the task of poverty is still arduous; increase of floating population, agricultural population into the cities and towns and population redistribution in different areas, the traditional economic and social management system and related produce a significant impact on population policy; improving the socialist market economic system in the process, the various contradictions and problems will emerge, and population and development issues facing the complexity remains.

In the sustainability impacts of many man-day factors, the population is very important. The amount of population and directly related to the consumption of resources, environmental protection, and is closely related to social and economic development. If the population into small, despite the natural resources and the environment can be effectively protected, but is detrimental to economic development, such as agriculture, water systems must be at man-days to reach a certain size in order to maximize the benefits; in commercial, industrial _ the party must also have a considerable number of man-days to form a market, promote the formation of effective demand production, and only a considerable number of man-days, can provide abundant labor, economies of scale effect; but the population is not possible, this it has been proved by historical experience. Our 
mountain in population size is too large, resulting in employment, many aspects of environmental protection, transportation, and social and economic development are under tremendous pressure, seriously affecting the sustainable development of our economy and society.

Demographic trends and the quality of economic development in various regions of China are basically the same, that is, the higher the quality of the population of the region, economic development faster, more slowly lower the quality of the population of the region and economic development. The same area and also improve the quality of the population to meet the economic development accelerated conclusion.

\section{Measures to Improve Population Quality}

Strengthen population health services and improve their physical fitness. The body is the capital of revolution, there is no strong physique and began things to always feel beyond their grasp. Therefore, improving the physical fitness of the population is essential to improve the quality of the population. As can be seen from the analysis of the results of the panel data model, the population levels of physical fitness four regions have significant impact on economic development, but the impact of the second region is not significant, and therefore, the second region should actively improve the physical fitness of the population increase it is in the role of promoting economic development. Specific measures are: First, to improve the quality of births. Take three precautions, basic knowledge of universal access to prevention of birth defects, pre-marital medical examination, to strengthen screening and treatment of birth defects; second, improve their health literacy. Spread advocate healthy and civilized life and behavior and open the supply of sports resources to carry out national fitness campaign, the prevention and control of AIDS and other communicable diseases; to create prevention-oriented public health system. Use of rural health care networks and family planning technical service network, to form a prevention-oriented public health service system, efforts to control serious harm infectious and endemic diseases, and better service for the majority of farmers.

Increase investment in education, to adjust the structure of education, to improve the cultural quality of the population. Research shows that if the initial stages of economic growth in human capital is abundant, then the transition is rapid economic growth, the level of economic equilibrium state is relatively high. Our data also proved this point, the first in the most economically developed regions, the population and cultural qualities and positive impact on the economic development of the most significant cultural quality of the population of the other three regions can not meet the needs of economic development. Therefore, in order to focus on these areas to improve the education quality of population-based. To improve the education quality of population, there is no doubt that education is the most effective way. Specific measures are: First, increase investment in education, clear responsibilities of governments at all levels in education, to ensure the supply of the education budget, and gradually increase the education budget in the proportion of the total production. Second, deepen education reform, to stimulate the vitality of educational development. Full implementation of quality education and promote the comprehensive development of man. Extend and consolidate compulsory education, vigorously develop vocational education, improve the quality of higher education. Third, the development of rural education in a prominent position, establish and improve compulsory education investment protection mechanism, will be fully integrated into compulsory coverage of public finance, in the countryside and gradually exempted from compulsory education tuition and fees in the city. Popularize scientific and cultural knowledge, the spirit of science, and continuously meet the people's growing cultural needs.

Strengthen the knowledge and skills training to improve the quality of labor skills of practitioners. Research shows that the quality of labor skills is the quality of our population "shortcomings" in the country to improve the quality of labor skills of practitioners to invest less, not more employment and training opportunities, leading to economic development and quality of labor skills are not in harmony. Thus, the region can take the following measures: First, strengthen graduates and migrant workers vocational and technical training, graduates lack of internship opportunities, not a good theoretical knowledge and practice, employment space is limited, and 
generally migrant workers there is a low level of literacy, lack of vocational skills and other issues, their employment space even smaller, poor ability to adapt. Especially with the accelerating industrialization and urbanization process, the quality of labor skills of migrant workers has an impact on the local social and economic development of human resources bottleneck. Second, all regions should vigorously develop vocational education, enrich social personnel structure optimization and upgrading of industrial structure to meet the demand for skilled personnel, rather than to the pursuit of higher education; Third, increase investment in science and technology, encourage innovation and invention, and constantly improve the R \& D capabilities .

Strengthen ideological and moral construction, improve population quality. Ideological and moral qualities is the quality of our population still another "short board", while the country's economic development, ideological and moral qualities are in the landslide, which is the idea of building a harmonious society is not consistent. Therefore, regions need to continue to enhance the people's moral qualities, to safeguard good social order. First, we must strengthen the legal system, crack down on various crimes, to form a good atmosphere for the development of social values and promote rapid economic development. Second, accelerate the pace of the humanities building, nurturing humanistic spirit, create a good atmosphere lively and civilized integrity, and strive to improve people's moral standards, form a positive folk customs; again, adhere to "grasp with both hands" approach , strengthen the socialist ideological and moral construction, firmly grasp the direction of socialist advanced culture, ideals and beliefs to carry out health education to the socialist core value system rooted in the mainstream of society and become the dominant values.

\section{Conclusion}

The quality of the population "short board" is in the way of local economic development. This is certainly not conducive to building a moderately prosperous society in an objective. In order to make the quality of our population and economic development coordination, countries and regions need to further enhance the quality of the population as an important infrastructure projects and major strategic task, different policies for different regions, targeted to improve the quality of the population.

\section{Acknowledgements}

Fund Project: "Utilization and Cross Development Mechanism Research on Chinese South Sea Nonrenewable resources" (16AJY008)

\section{References}

[1] Jia Xinzhang, Li Jingyuan. Northwest Population, Vol. 6 (2014) No 53, p.25-26

[2] Peng Sue, Wang Yunhui, Wang Qunyong. Population dynamics, Vol. 12 (2015) No 27, p.74-76

[3] Jing Jianfen. Shanxi University of Finance and Economics, Vol. 30 (2011) No 19, p.144-145

[4] Wang Kuailiang. China Population Science, Vol. 29 (2008) No 27, p.21-23

[5] Zhang Gongxu, Sun Jing. Population Research, Vol. 8 (2013) No 27, p.57-60 